\title{
Phenotypic modulation of fibroblastic cells in the mucous layer of the human uterine cervix at term
}

\author{
G. S. Montes ${ }^{1 \dagger}$, M. Zugaib2 ${ }^{2}$, P. P. Joazeiro ${ }^{3}$, J. Varayoud ${ }^{4}$, \\ J. G. Ramos ${ }^{4}$, M. Muñoz-de-Toro ${ }^{4}$ and E. H. Luque ${ }^{4 *}$ \\ ${ }^{1}$ Laboratory for Cell Biology, The University of São Paulo School of Medicine, Ave Dr \\ Arnaldo 455, São Paulo 01246-903, Brazil; '²Department of Obstetrics and Gynecology, \\ The University of São Paulo School of Medicine, Ave Dr Arnaldo 455, São Paulo 01246-903, \\ Brazil; ${ }^{3}$ Department of Histology and Embryology, Institute of Biology, UNICAMP, \\ Campinas-SP 13081-970, Brazil; and ${ }^{4}$ Laboratorio de Endocrinología y Tumores \\ Hormonodependientes, School of Biochemistry and Biological Sciences, \\ Universidad Nacional del Litoral, CC 242, 3000 Santa Fe, Argentina
}

The uterine cervix is a dynamic structure with a high capacity to adapt to different, even opposing, roles during the sequence of physiological events of gestation (for example, acting as a barrier to retain the fetus during pregnancy and dilating to allow delivery at term). Histoarchitectural changes of the uterine cervix allow its successful adaptation. The aim of this study was to investigate whether fibroblastic cell plasticity, described in the lamina propria of the rat uterine cervix at term, could be observed in women too. Biopsy specimens of nonpregnant and intrapartum human cervices were studied under the transmission electron microscope, and cytoskeletal differentiation markers were identified by immunohistochemistry under the light microscope. Desmin-positive cells were present in the mucous layer of the cervix during labour. These cells displayed cytoplasmic processes (typical of myofibroblasts) that also stained positively for vimentin. The main ultrastructural features for defining the myofibroblast under the electron microscope were also observed in these cells. However, cervices of non-pregnant women contained resident fibroblasts at the same location. Examination of the differentiation repertoire of fibroblastic cells in the mucous layer of the uterine cervix resulted in the characterization of myofibroblasts at term. The implications of the plasticity of fibroblastic-myofibroblastic cells in the physiological changes displayed in the uterine cervix during pregnancy, labour and postpartum involution require further investigation.

\section{Introduction}

After characterization of the plasticity of fibroblastic cell in the lamina propria of the rat uterine cervix at term (Varayoud et al., 2001), it was decided to investigate whether this phenomenon also occurs in women.

Although fibroblastic cells are considered to be of relatively uniform morphology, they are endowed with multiple functional properties: they play an essential role in the metabolism of the extracellular matrix, contribute to wound healing and are also involved in the pathogenesis of fibrotic processes (Sappino et al., 1990). Myofibroblasts are differentiated cells with morphological features intermediate between those of fibroblasts and smooth muscle cells (Powell et al., 1999; Eyden, 2001a).

It has been known for some time that, as term approaches,

*Correspondence

†Deceased

Email: eluque@fbcb.unl.edu.ar marked changes, such as a widespread collagen remodelling, and alterations in proteoglycan metabolism, polymorphonuclear infiltration and water imbibition, occur in the uterine cervix (Junqueira et al., 1980). These structural modifications are associated with the ripening that allows the cervix to dilate for parturition (Luque et al., 1998). These observations show that the uterine cervix is a dynamic structure with a high capacity to adapt to different, and even conflicting, physiological situations. Both of the above studies have focused on changes at the extracellular matrix and cervical invasion by polymorphonuclear leucocytes (little attention was given to the fibroblasts of the cellular compartment). The fibroblastic cells in the cervical stroma are mainly distributed in the fibrous ring that surrounds the mucous layer (Danforth, 1983).

The marked alterations in the structural architecture and biochemical composition of fibroblastic cells observed in different physiological and pathological situations indicates an important phenotypic plasticity that permits adaptation (Sappino et al., 1990; Schmitt-Graff et al., 1994). Changes in the cytoskeleton are among the most prominent features 
of fibroblastic cellular modulation: desmin, vimentin and $\alpha$ smooth muscle actin ( $\alpha$-SMA) are frequently expressed in a specific pathway of differentiation (Can et al., 1995; Holstein et al., 1996). The gentle contractile machinery represented by these cytoskeletal elements in the structure of microfilaments and intermediate filaments results in electron microscopy images that are useful for defining the myofibroblast (Eyden, 2001a,b).

The aim of present study was to examine the ultrastructural and immunohistochemical characteristics of fibroblastic cells of the mucous layer of biopsy specimens obtained from uterine cervices of non-pregnant and intrapartum women. The differential expression of cytoskeletal proteins, as well as the ultrastructural features identified by the present study indicate that in place of the resident fibroblasts of the mucous layer in non-pregnant cervices, a typical myofibroblastic-cell phenotype could be characterized in intrapartum biopsy specimens.

\section{Materials and Methods}

Archival tissues obtained from the patients involved in a study by Junqueira et al. (1980) of the structure of the human uterine cervix at term were used in the present study. Eight biopsy specimens of cervical tissue of normal patients obtained during parturition, and another eight biopsy specimens from non-pregnant, sexually active women were used in this study. From the original 26 patients involved in the previous study, the present cases were selected on the basis of the presence of at least two representative samples of tissues (one sample embedded in paraffin wax for light microscopy studies, and the other sample embedded in resin for electron microscopy) from each patient. Local institutional approval for the use of this archival material was obtained from the requisite authority before the start of the study.

Immunohistochemical detection of vimentin, desmin and $\alpha$-SMA was performed according to the protocol described by Varayoud et al. (2001) for the rat uterine cervix. In brief, after the paraffin wax was removed from the section, microwave pretreatment (antigen retrieval) was performed. The endogen peroxidase activity was inhibited and non-specific binding was blocked. Sections were incubated with mouse monoclonal antibodies (antibodies were used: anti-desmin (clon DER-11, Novocastra, Newcastle-upon-Tyne) 1:50, anti-vimentin (clon V9, Novocastra) 1:100 and anti- $\alpha$-SMA (clon $\alpha s m-1$, Novocastra) $1: 100$ ) for $3 \mathrm{~h}$ at room temperature. Reactions were developed using streptavidin-biotin peroxidase, and diaminobenzidine (DAB) (Sigma Chemical Co., St Louis, $\mathrm{MO}$ ) was used as a cromogen substrate for $10 \mathrm{~min}$ at room temperature. Samples were counterstained with Harris' haematoxylin (Biopur, Rosario) and mounted with permanent mounting medium (PMyR, Buenos Aires). Each immunohistochemical experiment included positive and negative controls. For negative controls, the primary antibody was replaced by non-immune mouse serum
(Sigma). The specificity of the primary antibodies used has been tested by the supplier.

Electron microscopy studies were performed as described by Junqueira et al. (1980) for human cervical tissues. In brief, small fragments of cervical biopsy specimens were fixed in $2 \%$ glutaraldehyde dissolved in $0.15 \mathrm{~mol} \mathrm{PBS} \mathrm{I}^{-1}$ at $\mathrm{pH} 7.2$, followed by rinsing in saline solution, post-fixed with $1 \% \mathrm{OsO}_{4}$ (Sigma), dehydrated with acetone and embedded in Epon 812 resin (Polyscience, Warrington, PA). Semithin sections were cut and stained with methylene blue. Representative areas of the lamina propria (using the epithelium and the basement membrane as a guide) and also of deeper regions, were selected. Ultrathin sections were studied under a transmission electron microscope (LEO Electron Microscopy Ltd, Oberkochen).

Ultrastructural features that characterize myofibroblastic cells were defined taking into account previous descriptions (Schmitt-Graff et al., 1994; Eyden, 2001a,b; Varayoud et al., 2001).

\section{Results}

In both the non-pregnant and intrapartum patients studied, fibroblastic cells of the mucous layer of the uterine cervix always stained positively with anti-vimentin, but did not react with anti- $\alpha$-SMA antiserum (Fig. 1). Immunohistochemical expression for vimentin was similar in intrapartum sections and sections from non-pregnant controls (Fig. 1a,d).

Although desmin expression could not be detected in fibroblastic cells of tissue from non-pregnant women (Fig. 1e), fibroblastic cells from cervices of intrapartum women reacted strongly with anti-desmin (Fig. 1b). The strong expression of desmin found in sections of cervices from intrapartum women corresponded to cells in the mucous layer that also stained positive for vimentin. The staining pattern for desmin in intrapartum specimens revealed the morphological characteristics of myofibroblasts: the strongly reacting halo that surrounded the nucleus, radiating through the cytoplasm, along well developed cytoplasmic processes, up to the cell membrane (Fig. 1b, inset).

In addition to light microscopy studies, electron microscopy observations were performed from the fibrous layer adjacent to the luminal epithelium (lamina propria) through the whole thickness of the cervical mucous layer. Ultrastructural examination of the cells in the mucous layer of cervices from intrapartum patients also disclosed features that corresponded to the typical characteristics of myofibroblasts. These cells displayed remarkable alterations in the size, shape and distribution of their organelles. An increase in total cell volume was observed, as well as a change in shape (from fusiform to round-ovoid) with large euchromatic nuclei (Fig. 2). Cells of cervices from intrapartum women had long cytoplasmic processes and their abundant cytoplasm contained much rough endoplasmic reticulum and many Golgi complexes (Fig. 3). Other ultrastructural 

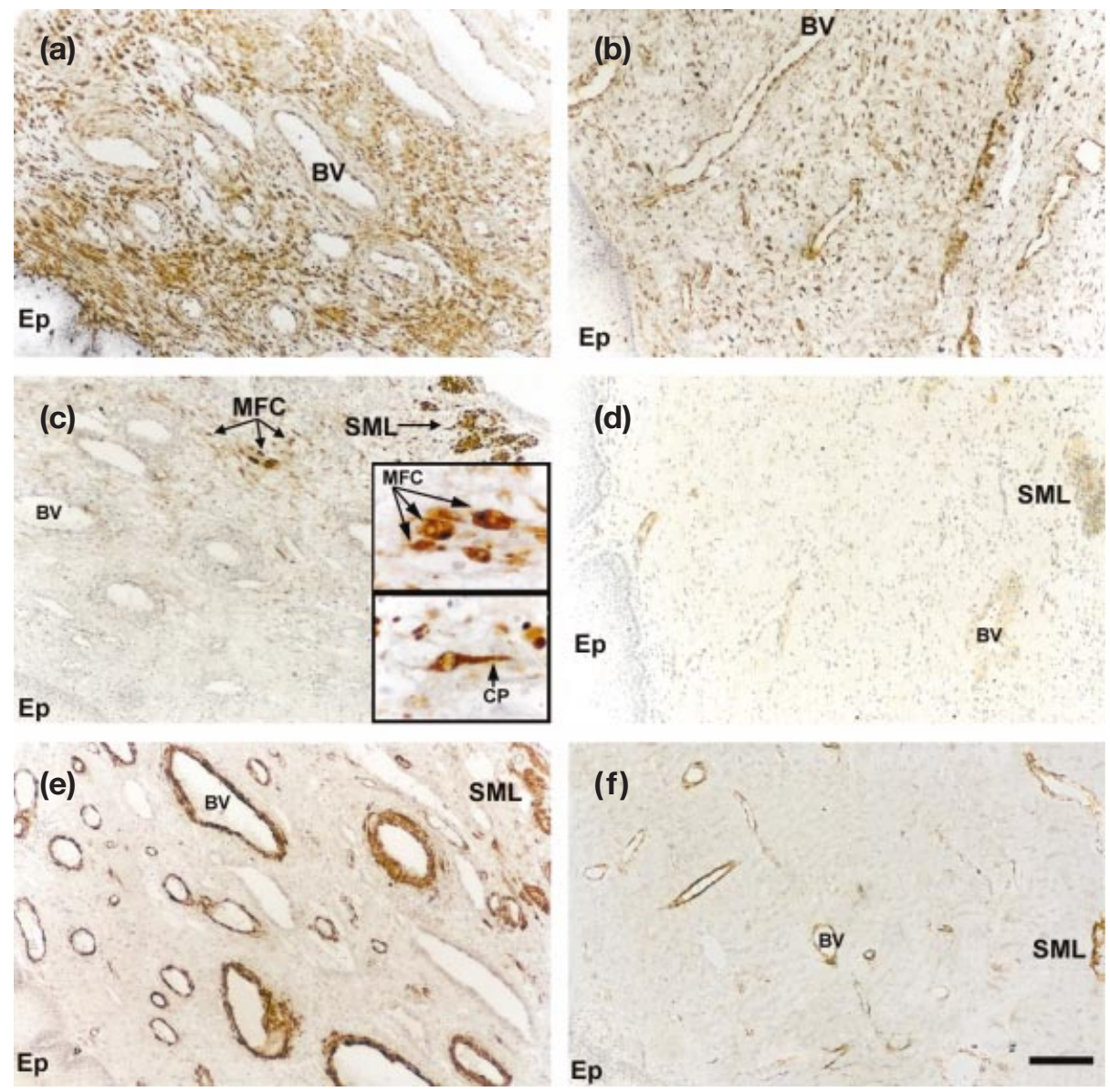

Fig. 1. Photomicrographs of sections from the uterine cervix of intrapartum $(a, c, e)$ and non-pregnant $(b, d, f)$ women. Sections were immunostained for $(a, b)$ vimentin, $(c, d)$ desmin and $(\mathrm{e}, \mathrm{f}) \alpha$-smooth muscle actin. Immunostaining for desmin in the uterine cervix of the intrapartum women shows a mucous layer of positive cells with cytoplasmic processes (myofibroblastic cells) that also stained positive for vimentin. Each inset shows the characteristic spindle shape of myofibroblastic cells at high magnification. MFC: myofibroblastic cell; CP: cytoplasmic process; Ep: epithelium; BV: blood vessel; SML: smooth muscle layer. Scale bar represents $200 \mu \mathrm{m}$.

features that could be observed at higher magnifications in cervical myofibroblastic cells included a few pinocytotic vesicles (caveolae) alongside the sub-plasmalemmal web of filaments (Fig. 3). The presence of junctional complexes between the interior of these myofibroblastic cells and the adjacent stroma is evident (Fig. 4); these structures possess the characteristics of the fibronexus junction, which is a transmembrane complex involving the point of convergence of intracellular microfilaments in apparent continuity with the extracellular matrix fibrillary structures. These junctions are considered to have a role in the transmission of contractile force within the tissue and are one of the distinctive characteristics of myofibroblasts. Linear densities and discontinuous thin strips of basal lamina-like material adjacent to the external surface of the cell membrane could also be observed (Fig. 4). Taken together, these ultrastructural features resemble the myofibroblastic phenotype defined in previous morphological descriptions and indicate both secretory and contractile roles.

Fibroblastic cells from non-pregnant controls displayed features of the different stages of fibroblastic function, showing a range from relatively undifferentiated (inactive) fusiform fibroblasts (that constitute the bulk of the cellular compartment; Fig. 5), to fibroblasts actively synthesizing extracellular matrix, to myofibroblastic-like cells.

\section{Discussion}

This study investigated the presence of cells with structural and biological properties between those of resident fibroblasts and those of smooth muscle cells in the mucous layer of the human uterine cervix at term. These cells were defined as myofibroblasts, because the ultrastructural features and the immunohistochemical expression of both 


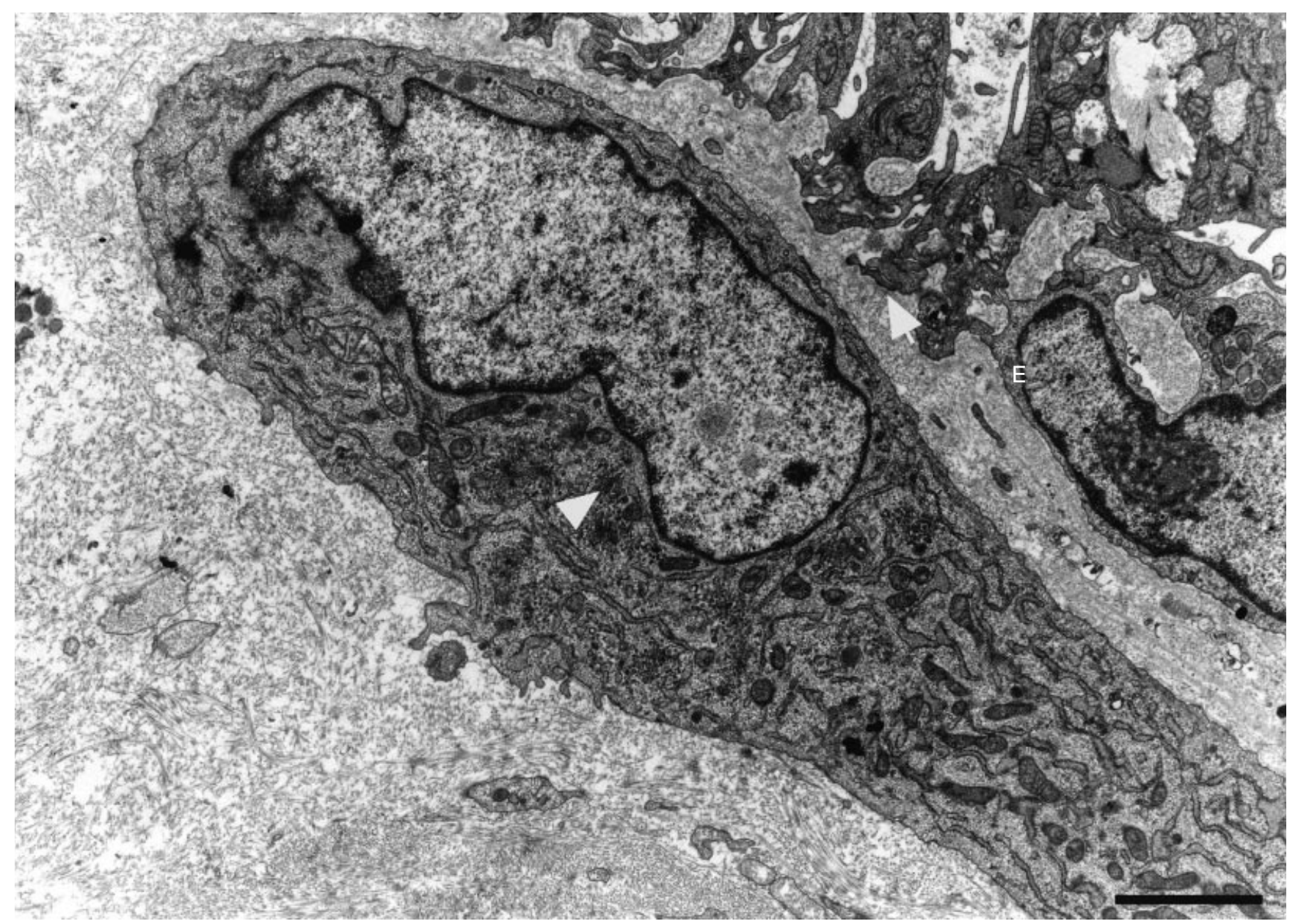

Fig. 2. Electron micrograph of a subepithelial myofibroblastic cell in the lamina propria of the uterine cervix of a woman during labour. Luminal epithelium (E) and its basement membrane (arrow). An indented nucleus can be seen. The well-developed rough endoplasmic reticulum and also the Golgi complex (arrowhead) indicate an active secretory role. Scale bar represents $2 \mu \mathrm{m}$.

vimentin and desmin are in agreement with other descriptions (Sappino et al., 1990; Eyden, 2001a,b). Immunohistochemical studies revealed heterogeneous cytoskeletal phenotypes among myofibroblasts in terms of intermediate filaments, smooth muscle actin and myosin expression. Although several studies have described myofibroblasts that co-express vimentin and $\alpha$-SMA (Sappino et al., 1990; Schmitt-Graff et al., 1994; Zhang et al., 1996; Powell et al., 1999; Eyden, 2001a), other reports provide evidence of vimentin- and desmin-positive myofibroblasts in normal organs (Can et al., 1995; Desmoulière and Gabbiani, 1996; Varayoud et al., 2001).

Understanding the complex molecular biology underlying the dynamic function of the uterine cervix is a basic problem in the physiology of gestation and parturition. During pregnancy, extensive tissue remodelling involves both the extracellular matrix and cells of the cervical tissue (Leppert, 1998). The cellular and extracellular compartments must adapt in a very short period to new functional demands imposed by gestation and parturition, and subsequently restore themselves during the following involution period. The present study provides a detailed description of the morphological and immunohistochemical features observed in the fibroblastic cells of the uterine cervix of intrapartum patients compared with samples from non-pregnant women.

Regionally specific changes might be expected in the uterine cervix because, at the end of pregnancy, the cervix should serve the dual, but conflicting, functions of acting as a barrier to retain the conceptus first, and then dilating at the time of delivery. This dynamic role of the uterine cervix is achieved by the interplay between the extracellular matrix and the cellular compartment. The extracellular matrix is susceptible to profound changes, such as a widespread collagen remodelling, changes in proteoglycan metabolism and uptake of water (Ludmir and Sehdev, 2000). However, in this changing environment, the cellular compartment (composed mainly of fibroblastic and smooth muscle cells) has to maintain the basic structure of the organ, including epithelial continuity and blood supply. Moreover, cytokines, 


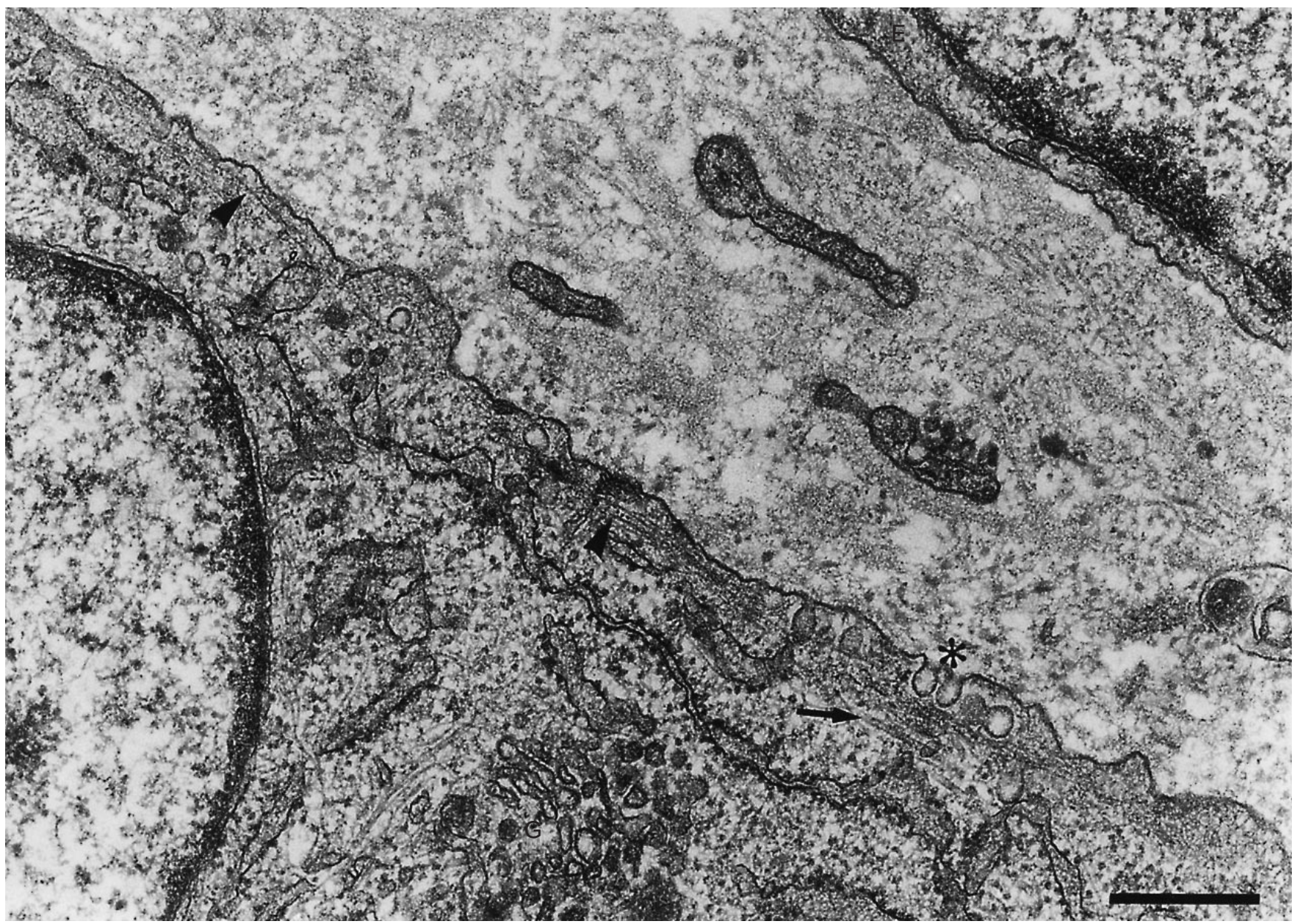

Fig. 3. This higher magnification of the cell shown in Fig. 2 shows the cell surface features of the myofibroblastic cell. The subplasmalemmal web of cytoskeletal elements can be seen: filaments (arrowheads) and microtubules (arrow). E: epithelium; G: Golgi complex; *: plasmalemmal caveolae (pinocytotic vesicles). Scale bar represents $0.39 \mu \mathrm{m}$.

and also macromolecules of the extracellular matrix, are known to stimulate the release of collagenases and elastaselike enzymes from cervical fibroblasts (Ludmir and Sehdev, 2000). Other cervical cells also show changes during pregnancy and parturition. Differences in the cellular turnover according to the cellular compartment of the uterine cervix and the stage of pregnancy considered were observed by Ramos et al. (2002).

The increased expression of desmin found at term might contribute to adaptations of the cellular compartment to the changes of the regional forces produced by alterations in the extracellular matrix composition. Therefore, given the role that microtubules, microfilaments and intermediate filaments play in determining cellular morphology and function, it is possible that desmin expression in myofibroblasts accounts for the rapid transformation of cell shape and organelle distribution as a consequence of increased synthetic activity of collagen and elastin fibres during pregnancy (Can et al., 1995).
An important aspect of the differential expression of desmin is its mechanism of control. In pregnant rats, it should be noted that desmin expression begins at midgestation and increases in parallel with the plasma concentrations of relaxin (Sherwood et al., 1983), reaching its highest expression at parturition (Varayoud et al., 2001). Moreover, immediately after delivery, both relaxin and desmin reach basal values. The results obtained from studies in rats indicate that desmin expression is a hormonally regulated process responsible for adaptation changes in the cervical tissue during pregnancy. However, it was also shown that progesterone is involved in differentiation and growth of stromal cells in both rat and human decidua (Dai and Ogle, 1999; McParland et al., 2000). The possible role of progesterone and relaxin in the regulation of the fibroblastic modulation observed in the uterine cervix needs to be investigated.

The fine structure of the cells found in the mucous layer of cervices from intrapartum women in the present study 


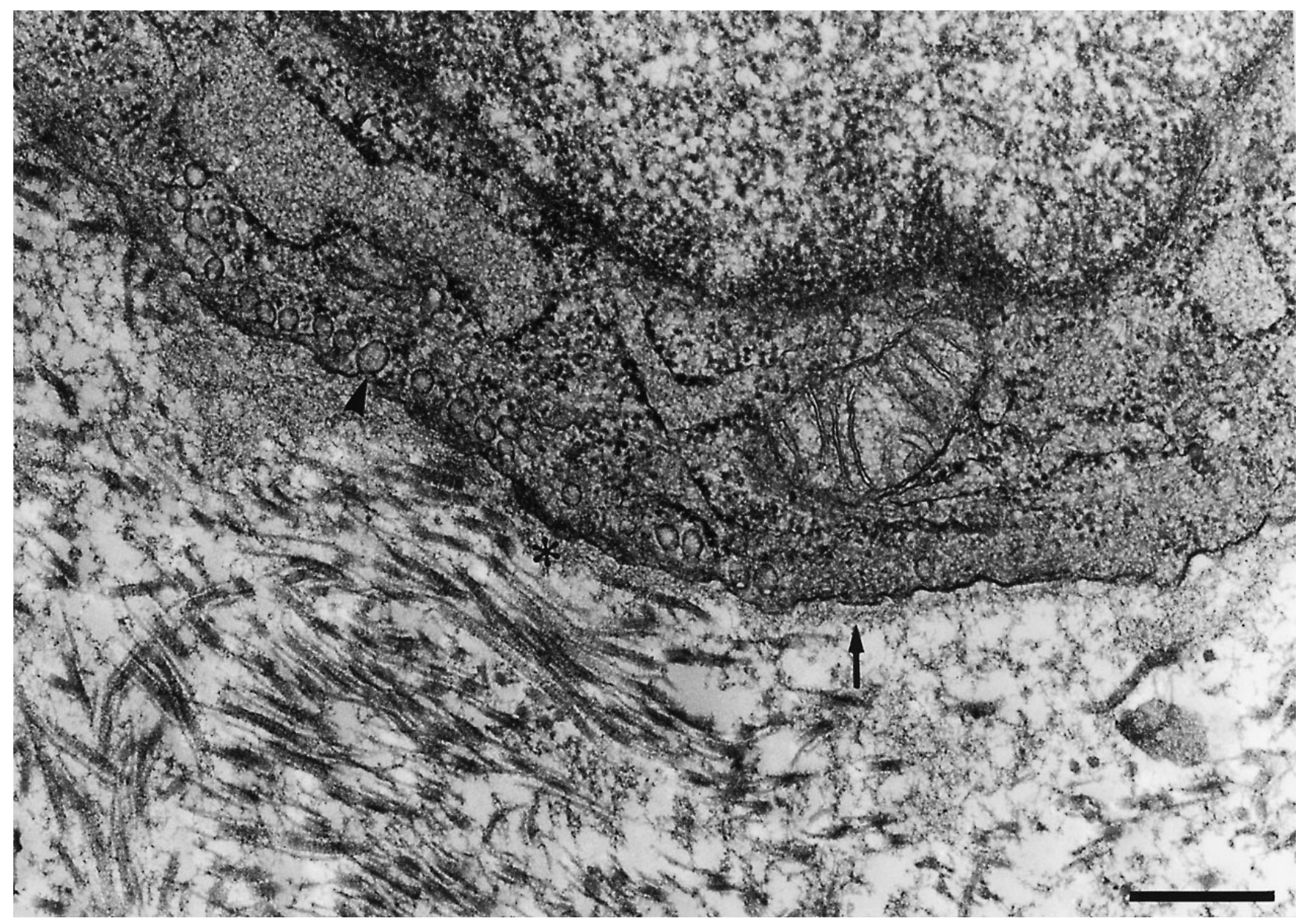

Fig. 4. Electron micrograph of a myofibroblast in the mucous layer of a human intrapartum cervix. The hemidesmosome-like structure $(*)$ corresponds to the so-called fibronexus junction. Note the abundant pinocytotic vesicles (arrowhead). An arrow points at basal lamina-like material. Scale bar represents $0.33 \mu \mathrm{m}$.

correspond to those described as the main electron microscopy features for defining the myofibroblast (Eyden, $2001 a, b)$. Taken together, the immunophenotype of the cytoskeletal proteins and the ultrastructural characteristics of the contractile apparatus indicate that an association of the cellular network interacting with the extracellular matrix (through the abundant fibronexus junctions present in the myofibroblasts) aid in supporting varying mechanical stress during labour. Subpopulations of fibroblastic cells may further refine the adaptation to regional differences in mechanical stress. Thus, it appears that a few of the ultrastructurally defined myofibroblastic cells in the lamina propria of cervices during labour (as well as some of these same cells in the mucous layer of non-pregnant biopsy specimens) were found in regions in which desmin reaction was absent. This observation indicates that a subset of myofibroblastic cells in these circumstances corresponds to a desmin-negative phenotype.

When compared with the rat cervical tissue at term, in which Varayoud et al. (2001) performed a morphometric study, the myofibroblasts observed in the human cervical tissue at term were much more abundant. The rat cervical myofibroblasts at term were scant and restricted to the subepithelial region, whereas in women they were distributed all through the mucous layer.

On the basis of the differential expression of desmin and the ultrastructural features, the foregoing results demonstrate that myofibroblasts are present in the mucous layer of the uterine cervix at term. Although further studies investigating the correlations between the morphological changes of the cervical fibroblasts and the dynamic changes of the mechanical environment are required to understand the role of these cells in cervical function at term, hypothetical roles may be put forward. It is well known that during wound healing the resident cells reassume the form and appearance of secreting fibroblasts. The myofibroblast, a cell with features of both fibroblasts and smooth muscle, is also observed during wound healing. These cells 


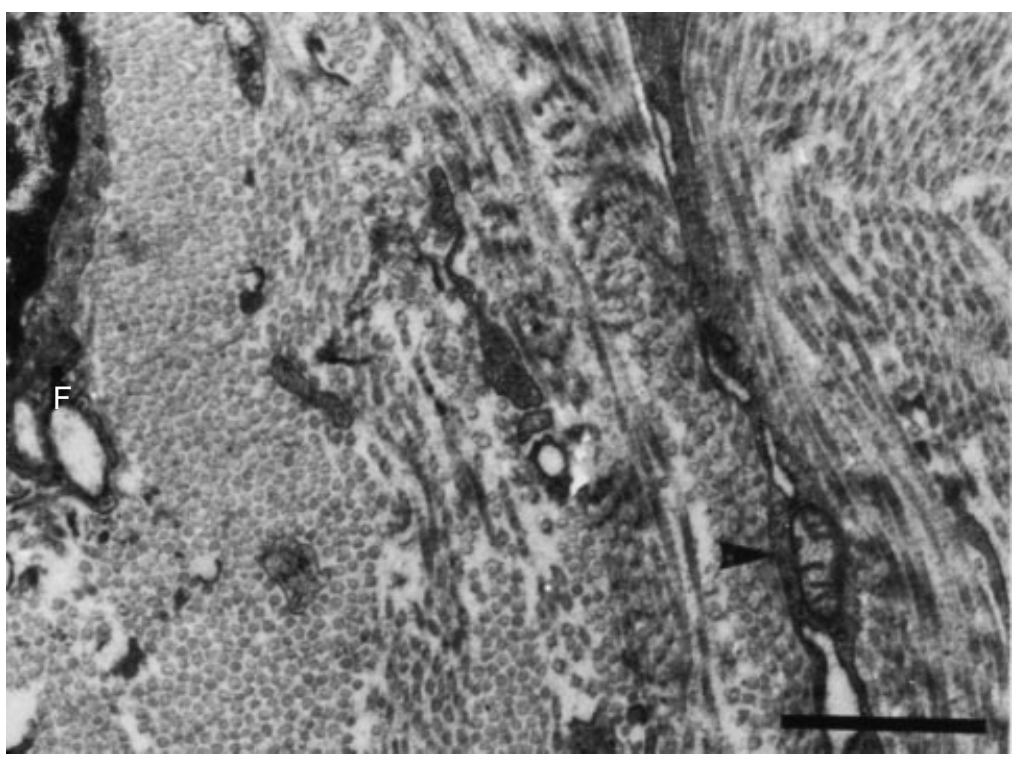

Fig. 5. Electron micrograph of the cervix of a non-pregnant woman. Bundles of collagen fibrils are interspersed with fibroblasts (F) and fibroblastic cytoplasmic processes (arrowhead). The scant cytoplasm and the very few cytoplasmic organelles are typical of quiescent cells. Scale bar represents $6.6 \mu \mathrm{m}$.

possess the morphological characteristics of an activated fibroblast but contain increased amounts of cytoskeletal elements. Their contractile activity is responsible for wound closure after tissue injury, a process called wound contraction (Desmoulière and Gabbiani, 1996). Perhaps the presence of many myofibroblasts in the mucous layer of the uterine cervix at term may account for the formation of a 'purse-string' ring around the lumen, the constriction of which may help to close the cervical canal after delivery.

This study was supported by grants from the Brazilian National Council for Scientific and Technological Development (CNPq 521342/96-1), the Argentine National Council for Science and Technology (CONICET - PIP 528/98), the Argentine National Agency for the Promotion of Science and Technology (PICT-99 5-7001), and the Agreements: CONICET/ CNPq (1786) and SECYTCAPES (BR04/99/OG). J. Varayoud and J. G. Ramos are Fellows of the CONICET; G. S. Montes was a Career Investigator of the CNPq, and E. H. Luque is a Career Investigator of the CONICET.

\section{References}

Can A, Tekelioglu M and Baltaci A (1995) Expression of desmin and vimentin intermediate filaments in human decidual cells during first trimester pregnancy Placenta 16 261-275

Dai D and Ogle TF (1999) Progesterone regulation of epidermal growth factor receptor in rat decidua basalis during pregnancy Biology of Reproduction 61 326-332

Danforth DN (1983) The morphology of the human cervix Clinical Obstetrics and Gynecology 26 7-13

Desmoulière A and Gabbiani G (1996) The role of the myofibroblast in wound healing and fibrocontractive diseases. In The Molecular and Cellular Biology of Wound Repair pp 391-423 Ed. RAF Clark. Plenum Press, New York
Eyden B (2001a) The myofibroblast: an assessment of controversial issues and a definition useful in diagnosis and research Ultrastructural Pathology 25 39-50

Eyden B (2001b) The fibronexus in reactive and tumoral myofibroblasts: further characterisation by electron microscopy Histology and Histopathology 16 57-70

Holstein AF, Maekawa M, Nagano T and Davidoff MS (1996) Myofibroblasts in the lamina propria of human seminiferous tubules are dynamic structures of heterogeneous phenotype Archives of Histology and Cytology 59 109-125

Junqueira LCU, Zugaib M, Montes GS, Toledo OMS, Krisztán RM and Shigihara KM (1980) Morphological and histochemical evidence for the occurrence of collagenolysis and for the role of neutrophilic polymorphonuclear leukocytes during cervical dilation American Journal of Obstetrics and Gynecology 138 273-281

Leppert PC (1998) The biochemistry and physiology of the uterine cervix during gestation and parturition Prenatal and Neonatal Medicine 3 103-105

Ludmir J and Sehdev HM (2000) Anatomy and physiology of the uterine cervix Clinical Obstetrics and Gynecology 43 433-439

Luque EH, Muñoz-de-Toro MM, Ramos JG, Rodríguez HA and Sherwood OD (1998) Role of relaxin and estrogen in the control of eosinophilic invasion and collagen remodeling in rat cervical tissue at term Biology of Reproduction 59 795-800

McParland PC, Taylor DJ and Bell SC (2000) Myofibroblastic differentiation in the connective tissues of the amnion and chorion of term human fetal membranes: implications for fetal membrane rupture and labour Placenta 21 44-53

Powell DW, Mifflin RC, Valentich JD, Crowe SE, Saada JI and West AB (1999) Myofibroblasts. I. Paracrine cells important in health and disease American Journal of Physiology 277 1-19

Ramos JG, Varayoud J, Bosquiazzo VL, Luque EH and Muñoz-de-Toro M (2002) Cellular turnover in the rat uterine cervix and its relationship to estrogen and progesterone receptor dynamics Biology of Reproduction $67735-742$

Sappino AP, Schürch W and Gabbiani G (1990) Differentiation repertoire of fibroblastic cells: expression of cytoskeletal proteins as marker of phenotypic modulations Laboratory Investigation 63 144-161 
Schmitt-Graff A, Desmoulière A and Gabbiani G (1994) Heterogeneity of myofibroblast phenotypic features: an example of fibroblastic cell plasticity Virchows Archiv 425 3-24

Sherwood OD, Downing SJ, Golos TG, Gordon WL and Tarbell MK (1983) Influence of light-dark cycle on antepartum serum relaxin and progesterone immunoreactivity levels and on birth in the rat Endocrinology 113 997-1003

Varayoud J, Ramos JG, Joazeiro PP, Montes GS, Muñoz-de-Toro MM and Luque EH (2001) Characterization of fibroblastic cell plasticity in the lamina propria of the rat uterine cervix at term Biology of Reproduction $65375-383$
Zhang HY, Gharaee-Kermani M, Zhang K, Karmiol S and Phan SH (1996) Lung fibroblast alpha-smooth muscle actin expression and contractile phenotype in bleomycin-induced pulmonary fibrosis American Journal of Pathology 148 527-537

Received 4 June 2002.

First decision 7 August 2002.

Revised manuscript received 2 September 2002.

Accepted 4 September 2002. 